\title{
REAKSI FISI DAN REAKSI FUSI DALAM MEKANISME BOM ATOM DAN SENJATA TERMONUKLIR
}

\author{
Endro Tri Susdarwono* \\ *Progam Studi Ilmu Komunikasi Universitas Peradaban, Jawa Tengah \\ Corresponding Author: midas999saniscara@gmail.com
}

DOI: $10.35719 /$ Vektor.v2i1.19

\begin{abstract}
Abstrak. Tujuan penelitian ini membahas mengenai reaksi fisi dan fusi pada bom atom dan senjata termonuklir. Penelitian ini adalah penelitian kualitatif, jenis penelitiannya menggunakan studi analitik komprehensif. Bagian paling vital dari ledakan fisi yang terjadi dalam bom atom tak lain adalah material yang berfisi itu sendiri. Ada dua unsur radioaktif yang biasa dipakai, yakni uranium dan plutonium, masing-masing dengan aneka isotopnya. Mulai dari U-232, U-234, U-235, dan U238 untuk uranium, hingga Pu-238, Pu-239, dan Pu240 untuk plutonium. Elemen pemicu ledak yang dipakai dalam ledakan termonuklir ialah deuterium (D) alias hydrogen berat atau yang juga popular dengan sebutan 'air berat' (heavy water). Dari setiap 5000 atom hydrogen, bisa dipastikan satu isotop di antaranya dalam bentuk deuterium. Inti deuterium (deutron) terdiri dari satu proton (p) dan satu neutron ( $n)$. saat berpasangan, dua deutron membentuk inti atom helium ( $\mathrm{He}-4)$ yang relatif stabil. Dalam semua jenis reaksi ini, inti atom berat terbentuk melalui proses fusi.
\end{abstract}

Kata Kunci: bom atom, reaksi fisi, reaksi fusi, senjata termonuklir

Abstract. The purpose of this research is to discuss fission and fusion reactions in atomic bombs and thermonuclear weapons. This research is a qualitative research. This type of research uses a comprehensive analytical study. The most vital part of the fission explosion that occurs in an atomic bomb is none other than the fission material itself. There are two radioactive elements in common use, uranium and plutonium, each with its different isotopes. They range from U-232, U234, U-235, and U-238 for uranium, to Pu-238, Pu-239, and Pu240 for plutonium. The explosive trigger element used in thermonuclear explosions is deuterium (D) heavy hydrogen or also popularly known as "heavy water" (heavy water). For every 5000 hydrogen atoms, one can be sure of one of them in the form of deuterium. The nucleus of heuterium (deutron) consists of one proton $(p)$ and one neutron $(n)$. When paired, the two deutrons form a relatively stable nucleus of helium (He-4). In all of these types of reactions, heavy atomic nuclei are formed by fusion.

Keywords: atomic bombs, fission reactions, fusion reactions, thermonuclear weapons

\section{PENDAHULUAN}

Nuklir adalah padanan kata dalam bahasa Indonesia yang diambil dari kata dalam bahasa Inggris yaitu: nuclear yang berarti inti atom. Sedangkan kata nuclear itu sendiri berasal dari bahasa latin: nucleus yang berarti inti. Berdasarkan konsep fisika maupun kimia, atom adalah bagian terkecil dari suatu materi yang masih memiliki sifat dasar materi tersebut. Atom walaupun sangat kecil, akan tetapi atom mempunyai ukuran (diameter) yaitu sekitar 1 Angstrom atau $10^{-8} \mathrm{~cm}$. sedangkan ukuran inti atom atau ukuran nuklir lebih kecil yaitu $10^{-4}$ Angstrom atau sama dengan $10^{12} \mathrm{~cm}$. ini lebih kecil 
lagi, $1 \mathrm{~cm}$ dibagi 1.000 .000 masih dibagi dengan 1.000 .000 itulah ukuran inti atom atau nuklir (Wardhana, 2009).

Energi nuklir adalah energi yang dihasilkan dari reaksi inti. Reaksi inti ada 2 macam, yaitu reaksi pembelahan (reaksi fisi) dan reaksi penggabungan (reaksi fusi) yang kedua-duanya menghasilkan suatu energi yang sangat besar. Kedua jenis tersebut memiliki pembentukan energi melalui cara yang berbeda. Nuklir fisi dengan pemecahan inti berat, sedangkan nuklir fusi dengan penggabungan inti ringan (Maemunah, dkk., 2019). Reaksi fisi dan reaksi fusi merupakan reaksi yang eksoergik sehingga dapat diperkirakan besarnya energi yang menyertai reaksi penembakan inti (transmutasi inti) (Sukarna, 1997). Pada reaksi fisi, neutron yang tidak mempunyai muatan listrik dapat dengan mudah mendekati dan bereaksi dengan inti dapat belah, seperti uranium-235. Tetapi pada reaksi fusi, kedua inti yang bereaksi mempunyai muatan listrik positif dan gaya tolak menolak antara mereka yang disebut gaya Coulomb yang harus diatasi agar kedua inti tersebut dapat bersatu (Agung, 1998).

Senjata nuklir adalah alat peledak yang mendapatkan daya ledaknya dari reaksi nuklir, baik itu reaksi fisi atau kombinasi dari fisi dan fusi. Keduanya melepaskan sejumlah besar energi dan sejumlah kecil massa, bahkan alat peledak nuklir kecil dapat menghancurkan sebuah kota dengan ledakan, api, dan radiasi (Basri, 2014).

Dunia ilmu pengetahuan mengenal adanya radioaktivitas yang dipancarkan oleh suatu atom yang radioaktif seperti halnya Uranium berkat Marie Curie. Penelitian tentang atom dan radioaktivitas berkembang terus yang kemudian membawa kita pada penemuan reaksi pembelahan atom untuk pertama kalinya oleh ilmuwan Jerman bernama Otto Hahn dan Fritz Strassman (tahun 1938). Pada saat itu reaksi pembelahan atom yang merupakan reaksi inti atom sangat menarik perhatian para ilmuwan karena energi yang dihasilkan dari reaksi pembelahan tersebut sangat besar. Reaksi pembelahan atom yang terjadi pada waktu itu belum bisa dikendalikan. Reaksi inti yang bisa dikendalikan ditemukan pertama kali oleh ilmuwan Italia yang hijrah ke Amerika Serikat bernama Enrico Fermi (tahun 1942). Penemuan ini sangat bersejarah bagi umat manusia, karena mulai saat itu orang akan dapat memanfaatkan energi yang sangat besar yang dihasilkan oleh reaksi inti pembelahan atom. Untuk pertama kalinya energi yang sangat besar tersebut digunakan dalam bom atom yang dijatuhkan di Hiroshima dan Nagasaki yang mengakhiri perang dunia ke dua. Energi yang sangat besar dihasilkan dari pancaran radiasi suatu atom radioaktif dan reaksi pembelahan inti atom (Wardhana, 2009).

Kemajuan di bidang fisika nuklir telah membawa manusia untuk selangkah lebih maju menuju tercapainya kesejahteraan manusia. Hal ini diilhami oleh penemuan fisi nuklir oleh empat ilmuwan Jerman; Otto Hahn, Lise Meitner, Fritz Strassman, dan Otto Frisch pada tahun 1939. Mereka menemukan bahwa penembakan inti berat dengan neutron dapat menghasilkan inti belah dan dihasilkan sejumlah energi. Sejak penemuan fisi nuklir tersebut perkembangan di bidang fisika nuklir tak terelakkan lagi (Wiyatmo, 2014).

Proses fisi ditemukan oleh Hahn dan Strassman (1939) dengan percobaan radiokimia. Mereka menunjukkan bahwa penembakan uranium dengan neutron menghasilkan unsur-unsur menengah dalam tabel periodik, dan unsur-unsur transuranium yang telah diyakini sebelumnya. Dua komponen inti utama dikenal sebagai fragmen fisi, yang secara energetika tidak memiliki massa yang sama. Distribusi massa mungkin dipengaruhi oleh efek kulit. Fragmen fisi bersifat tidak stabil, hal ini disebabkan kedua fragmen dalam proses fisi menangkap rasio neutron-proton yang sama dengan inti majemuk asli, yang letaknya di dekat garis kestabilan. Fragmen-fragmen tersebut sangat kaya neutron. Oleh karena peluruhan yang terjadi lebih terkenal dengan emisi neutron. Peluruhan beta negatif dan peluruhan gamma sebenarnya juga terjadi pada hasil fisi. Pada beberapa kasus keadaan eksitasi, yang terletak di atas energi separasi neutron dihuni oleh peluruhan beta, sehingga terjadi emisi neutron tunda. 
Teori asli tentang proses fisi dikembangkan oleh Bohr dan Wheeler (1939) didasarkan pada model tetes cairan. Proses tersebut secara sederhana digambarkan bahwa energi ikat tangkapan neutron menyebabkan inti majemuk bergetar secara hebat, sehingga inti terbelah. Neutron-neutron dipancarkan dari inti. Beberapa fragmen fisi terbentuk dalam keadaan eksitasi dan meluruh dengan memancarkan radiasi gamma dengan umur hidup $10^{-15} \mathrm{~s} / \mathrm{d} 10^{-13}$ sekon, selanjutnya fragmen fisi meluruh dengan peluruhan beta negatif menuju garis kestabilan. Jika kita menghitung energi yang dibebaskan pada proses fisi sedemikian hingga inti $(A, Z)$ terbelah menjadi dua buah inti $(1 / 2 A, 1 / 2 Z)$, yang dikenal dengan fisi simetris, diperoleh dari rumus massa semiempiris bahwa untuk nuklida $\mathrm{A}>85$ bahwa $\mathrm{Q}>0$ (positif). Pada inti-inti ringan tidak terjadi fisi spontan, karena pada inti-inti ini terdapat perintang fisi.

Terkait dengan perkembangan awal reaksi fusi, Dr. Bethe mulai dengan dua buah keterangan yang telah teruji. Pertama, bahwa inti matahari melambung ke suatu suhu hampir 30 juta Fahrenheit. Kedua, bahwa bagian terdalam matahari mengandung jumlah besar hidrogen yang dikempa oleh tekanan luar biasa oleh selubung luar gas panas yang besar. Ia tahu bahwa panas dari tanur matahari ini keluar pada suatu kecepatan tertentu, yang diukur oleh ahli-ahli astro fisika sama dengan sepertiga triliun kilowatt. Jumlah tenga ini dibutuhkan untuk mempertanggungjawabkan panas yang menimpa bumi (Lapp, 1961).

Informasi laboratorium menunjukkan bahwa dua atom hidrogen yang saling berbenturan pada kecepatan tinggi, dapat bergabung menjadi satu. Sintese empat buah atom hidrogen membentuk satu atom helium, unsur berikutnya yang terberat dalam susunan berkala unsur-unsur. Dalam perubahan hidrogen ke helium, setiap atom hidrogen melepaskan sebagian kecil massanya. Hasilnya adalah bahwa massa empat atom hidrogen, sebelum fusi, sedikit lebih besar dari pada sesudah sintese ke dalam satu atom tinggi helium. Walhasil sebagian massa atom "hilang" dalam proses fusi (perpaduan). Teori Kenisbian (relativitas) khusus Einstein menetapkan hubungan masa energi yang sekarang telah terkenal yaitu $\mathrm{E}$ sama dengan $\mathrm{mc}^{2}$. $\mathrm{E}$ tanda untuk energi, $\mathrm{m}$ untuk massa dan c adalah tanda untuk kecepatan cahaya - sebuah konstan yang masuk dalam rumus ilmu pasti itu. Menurut hubungan Einstein, sejumlah sangat kecil benda adalah equivalen dengan sejumlah besar energi. Misalnya, benda di dalam sebuah tablet aspirin ukuran biasa, kalau seluruhnya diubah menjadi enegi, sama dengan kekuatan hampir 20 juta pon bahan peledak TNT.

Dr. Bethe menghitung bahwa jauh di dalam inti matahari yang panas itu, atomatom hidrogen akan selalu berbenturan dan walaupun atom-atom itu bergerak dengan kecepatan jauh lebih kurang dari kecepatan yang dicapai dalam cyclotron, beberapa atom akan berpadu untuk membentuk helium. Proses ini dikenal di kalangan teknik sebagai suatu reaksi thermonuklir atau lebih mudah digambarkan sebagai pembakaran nuklir. Perincian-perincian teorinya adalah telampau ruwet untuk dibicarakan di sini, yang penting adalah bahwa perhitungan $\mathrm{Dr}$. Bethe menunjukkan bahwa pembakaran hidrogen untuk membentuk helium dengan memuaskan bertanggung jawab bagi pengeluaran energi yang besar dari matahari.

Kembali ke matahari, adanya jumlah hidrogen yang besar di dalam inti pusat yang panas menyiapkan panggung untuk babak perttama drama thermonuklir. Tanur matahari siap untuk pencetusan. Dengan berangsur-angsur tubrukan baur atom-atom hidrogen yang mempunyai kecepatan tinggi, menghasilkan fusi dan mengeluarkan energi. Hal ini sebaliknya mempertinggi suhu inti dan atom-atom hidrogen memperoleh tambahan kecepatan (reaksi fusi hidrogen sangat peka terhadap kecepatan atau "suhu" atom-atom hidrogen; semakin tinggi kecepatan, semakin mudah terjadi fusi). Dengan tidak ada akhirnya, proses ini berulang sampai matahari mencapai suhunya sekarang. Suatu perimbangan yang tepat diperoleh antara kecenderungan suhu untuk naik lebih tinggi dan ukuran matahari yang karena menggembung oleh tekanan panas pusat yang lebih besar, mengambil suatu ukuran baru dan kemampuan untuk memancarkan panas dari permukaannya. Pendinginan dan kontraksi inti diimbangi oleh pengerutan selubung luar 
matahari dan sesuai dengan itu pemanasan kompresif. Jadi matahari telah membuktikan sebagai sesuatu yang mengatur dirinya sendiri, yang mempunyai suatu alat pengimbang panas (thermostat) sendiri untuk memelihara suhunya. Itulah sebabnya mengapa tata planet selalu mandi dalam panas matahari yang sama sejak lima biliun tahun yang lalu.

Ketika sebuah benda menyerap energi - sebagai contoh, dengan bertambah panas - maka "massa proper" nya sedikit meningkat. Peningkatan tersebut sangat kecil, karena diukur dengan cara membagi peningkatan energinya dengan kuadrat (square) kecepatan cahayanya. Pada sisi lain, ketika sebuah benda melepaskan energi maka benda tersebut kehilangan massa. Contoh yang paling terkenal mengenai fakta ini adalah bahwa empat atom hidrogen dapat berpadu untuk membentuk satu atom helium, sedangkan sebuah atom helium memiliki massa yang sedikit lebih kecil daripada empat kali massa dari satu atom hidrogen. Fenomena ini memiliki makna praktis yang sangat besar. Fenomena ini diduga terjadi di dalam tubuh dari bintang-bintang, yang memunculkan energi yang kita lihat sebagai cahaya bintang dan yang, dalam kasus matahari, menopang kehidupan bumi. Fenomena tersebut juga dapat dimunculkan di dalam laboratorium-laboratorium di bumi, dengan pelepasan energi yang luar biasa besar ke dalam bentuk cahaya dan hawa panas. Hal ini memungkinkan diciptakannya bom-bom hidrogen, yang nyaris tak terbatas dari segi jumlah dan daya rusaknya. Bom-bom atom sederhana yang muncul melalui disintegrasi uranium, memiliki keterbatasan alami: apabila terlalu banyak uranium dikumpulkan pada satu tempat, kumpulan uranium tersebut rawan untuk meledak sendiri, tanpa menunggu diledakkan, sehingga bom-bom uranium tidak dapat dibuat dalam jumlah lebih dari ukuran maksimum tertentu. Tetapi sebuah bom hidrogen dapat mengandung hidrogen sebanyak yang kita sukai, karena hidrogen itu sendiri tidak bersifat mudah meledak. Hanya ketika hidrogen diledakkan dengan bom uranium konvensionallah yang menjadikan unsur tersebut bergabung untuk membentuk helium dan melepaskan energi. Hal ini karena kombinasi tersebut hanya dapat terjadi pada suhu yang sangat tinggi [8]. Penelitian ini bermaksud untuk memberikan gambaran reaksi fisi dan reaksi fusi dalam mekanisme peledakan bom atom dan senjata termonuklir. Gambaran atau deskripsi yang diberikan diharapkan mampu memberikan pemahaman mengenai Pendidikan IPA khususnya yang terkait dengan pengembangan energi di masa yang akan datang.

\section{METODE}

Penelitian ini adalah penelitian kualitatif, jenis penelitiannya menggunakan studi analitik komprehensif. Studi analitik komprehensif adalah suatu cara berpikir yang mengkaji segala sesuatu dengan menyeluruh sehingga tidak terdapat lagi bagian yang tersisa ataupun berada di luarnya. Metode yang digunakan adalah studi pustaka ataupun literatur review yang sangat diperlukan untuk mengokohkan landasan ilmu yang akan dipaparkan dalam penelitian ini. Literatur review yang merupakan penjelasan baik dari teori, penemuan, maupun penelitian. Langkah ini lebih banyak dipakai untuk membenchmark pengetahuan umum agar memperkaya khazanah bahasan per-nuklir-an dalam bahasa Indonesia, selain juga memuat analisis berupa kritik ilmiah yang didapat dari pembelajaran yang cukup panjang. Literatur review ini banyak membahas ulasan, rangkuman ide dari berbagai penulis dan sumber pustaka yang berfdokus pada topik reaksi fisi dan reaksi fusi dalam mekanisme peledakan bom atom dan senjata termonuklir. 


\section{HASIL DAN PEMBAHASAN}

\section{Tinjauan Fisis Atom Hidrogen}

Penemuan Thomson (1912) tentang sejumah spesies atom dengan sifat-sifat kimia yang identik namun memiliki massa berbeda yang disebut isotop, mendorong perkembangan ke arah penentuan massa atom atau inti secara lebih teliti. Cabang khusus ini dalam fisika inti dirintis oleh Aston pada tahun 1917 yang dikenal sebagai spektroskopi massa. Pentingnya cabang ini dapat dilihat dari kenyataan bahwa sejumlah besar informasi mengenai gaya dan struktur inti dapat diperoleh dari hasil pengukuran masa secara teliti, yang di antaranya menunjukkan adanya perbedaan ruas kanan dan kiri persamaan sebesar tenaga ikat inti. Menurut model proton-neutron, deuterium memiliki sebuah proton dan sebuah neutron. Masing-masing nucleon mempunyai spin intrinsic $1 / 2$, sehingga spin total yang mungkin adalah 0 (jika dua spin tersebut berlawanan arah) atau 1 (jika kedua spin searah) (Wiyatmo, 2014).

Di antara tahun 1919, ketika Rutherford mengumumkan penemuannya tentang transmutasi nuklir buatan ${ }_{2}^{4} H_{e}+{ }_{7}^{14} N \rightarrow{ }_{1}^{1} H+{ }_{8}^{17} \mathrm{O}$ dan tahun 1939, ketika reaksi fisi ditemukan oleh Hahn, Stassman, Meitner, dan Frisch; hampir seluruh pengetahuan tentang proses nuklir yang dapat dihasilkan dengan energi penembakan di atas $10 \mathrm{MeV}$ telah ditemukan. Karena kemudian energi penembakan inti telah dapat ditingkatkan sampai orde $10 \mathrm{BeV}$, dan banyak tipe-tipe baru raksi inti yang telah dihasilkan, termasuk meson dan zarah-zarah tak stabil lainnya. Meskipun sekarang telah jelas bahwa zarahzarah tersebut memainkan peran penting dalam gaya inti.

Seperti yang sudah dipahami secara umum bahwa kelemahan teori Rutherford disempurnakan oleh Bohr dengan menambahkan 2 postulat (pengandaian), yaitu:

1. Setiap electron akan berputar mengelilingi inti atom dalam lintasan (orbit) tertentu dan secara fisis perputarannya mempunyai momentum sudut tertentu.

2. Suatu atom tidak akan memancarkan radiasi atau menerima (menyerap radiasi), apabila elektron yang mengelilingi inti masih tetap pada jalur lintasannya (orbit) asalnya. Apabila elektron mengalami perubahan jalur lintasan (orbit), maka atom tersebut akan memancarkan radiasi atau menerima radiasi (menyerap radiasi)

Selain dari postulat tersebut di atas, perlu juga diketahui bahwa dalam konsep atom modern yang dianut saat ini, jumlah electron pada setiap orbit (lintasan) atau kulit electron telah dikeahui jumlahnya. Jumlah electron untuk setiap orbit (lintasan) atau kulit electron ditentukan berdasarkan persamaan Pauli, yaitu: jumlah electron per kulit electron $=2 n^{2}$, $n$ dalam hal ini adalah nomor kulit electron (Wardhana, 2009).

Dan tidak kalah penting bahwa untuk dapat memahami kajian ini secara utuh maka harus memahami mengenai postulat Bohr, berikut disampaikan postulat Bohr.

\section{Postulat 1}

Atom hydrogen terdiri dari sebuah electron yang bergerak dalam suatu lintas edar berupa lingkaran mengelilingi inti atom; gerak electron tersebut dipengaruhi oleh gaya tarik Coulomb sesuai dengan kaidah mekanika klasik. Postulat 1 memberikan susunan atom hydrogen dan gaya yang bekerja antara inti atom dengan electron.

Postulat 2

Lintas edar electron dalam atom hydrogen yang mantap, hanyalah yang mempunyai harga momentum sudut $L$ yang merupakan kelipatan bilangan bulat dari tetapan Planck dibagi2 $\pi . \quad L=n h=n \frac{h}{2 \pi}$. Postulat 2 memberikan kuantisasi sistem atom, yang 
dikuantisasikan adalah momentum sudut L. Kuantisasi ini juga mengkuantisasikan lintas edar electron dalam atom.

\section{Postulat 3}

Dalam lintas edar yang mantap, electron yang mengelilingi inti atom tidak memancarkan energi eletromagnetic, dalam hal ini energi total atom $E$ tidak berubah. Postulat 3 menyatakan bahwa electron dalam orbit stasioner tidak memancarkan energi elektromagnetik.

\section{Postulat 4}

Energi elektromagnetik dipancarkan oleh sistem atom apabila sutu electron yang melintasi orbit mantap dengan energi $E_{i}$ secara tak sinambung berpindah ke suatu orbit mantap lainnya berenergi $E_{f}$, pancaran energi elektro magnetiknya memiliki frekuensi yang besarnya sama dengan: $v=\frac{E_{i}-E_{f}}{h}$. Postulat 4 menyatakan bahwa dalam transisi dari suatu orbit stabil ke orbit stabil lainnya, electron memancarkan energi elektromagnetik (foton) dengan frekuensi yang sesuai dengan beda energi atom pada dua keadaan stabil tersebut.

Rasa keinginan tahu berapa sebenarnya berat satu atom, telah mendorong para ilmuwan untuk menyelidiki lebih lanjut pengetahuan tentang atom. Seperti telah dikemukakan oleh Bohr, atom itu terbagi lagi menjadi bagian-bagian yang lebih kecil yaitu: inti atom (nuklir), electron-elektron yang berputar mengelilingi inti sesuai dengan orbit masing-masing electron. Sedangkan inti atom masih dibagi lagi menjadi: proton dan neutron. Jadi atom dibagi menjadi bagian-bagian yang lebih kecil: proton, neutron dan electron. Para ilmuwan saat ini dengan berbagai macam eksperimen tlah dapat menenukan berat proton $1,673 \times 10^{-27} \mathrm{~kg}$, berat neutron $1,675 \times 10^{-27} \mathrm{~kg}$, dan berat electron 9,109 x $10^{-31} \mathrm{~kg}$.

Menurut model atom, proton bermuatan listrik positif, neutron sesuai dengan namanya "neutral" berarti tidak bermuatan listrik, sedangkan electron bermuatan listrik negatif. Jadi singkat kata, inti (nuklir) bermuatan positif dan dikelilingi electron yang bermuatan negatif. Adanya inti atom (nuklir) yang bermuatan listrik positif dan electron yang bermutan listrik negatif, maka kedua partikel tersebut (yaitu: inti atom dan electron) akan menjadi sebuah pasangan dan menurut hukum Coulomb akan terjadi daya tarik menarik antara kedua pasangan tersebut.

Atom yang mempunyai jumlah electron dan proton sama, maka atom tersebut juga akan berada dalam keseimbangan. Pada penelitian lebih jauh mengenai atom, akan diketahi bahwa bila jumlah proton dan electron tidak sama, maka atom tersebut akan menjadi tidak seimbang. Untuk mencapai keseimbangannya, atom akan melepaskan kelebihan proton atau elektronnya yang di dalam ilmu fisika radiasi dikenal dengan memancarkan radiasi. Sebagai contoh, atom yang kelebihan proton akan mengeluarkan protonnya dan ini yang disebut dengan pancaran radiasi positron atau beta positif. Sedangkan atom yang kelebihan electron akan mengeluarkan elektronnya dan ini yang disebut dengan pancaran radiasi negatron atau radiasi beta negatif.

Kembali kepada teori model atom yang menyatakan bahwa electron berputar mengelilingi inti atom dengan lintasan atau orbit tertentu, kiranya para ilmuwan sdikit banyak terpengaruhi oleh adanya lintasan planet-planet yang berputar mengelilingi matahari yang ada di dalam tata surya kita ini, sehingga mereka (para ilmuwan) pun mengira bahwa electron-elektron berperilaku seperti halnya planet-planet yang mengitari matahari sesuai dengan lintasan atau orbitnya masing-masing. 
Jadi electron (yang bermuatan negatif) yang berputar mengelilingi inti (yang bermuatan positif) adalah dalam rangka atom mencari keseimbangan dirinya. Keseimbangan ini dicapai bila electron berputar mengelilingi inti selalu berada pada garis edarnya (orbit electron), bila tidak berada dalam orbitnya maka atom tidak berada dalam keseimbangannya.

Menurut Rutherford muatan listrik positif dan sebagian besar massa sebuah atom akan berkumpul pada satu titik di tengah-tengah atom yang disebut inti atom. Di luar inti pada jarak yang realtif jauh dari inti, electron-elektron beredar mengelilingi inti dalam lintasan sama seperti planet-planet mengelilingi matahari.

Untuk atom hydrogen, perbandingan garis tengah electron dengan garis tengah inti sekitar 10.000: 1. Sebagian besar dari atom merupakan ruangan kosong. Massa atom hampir seluruhnya terletak pada massa intinya, dengan perbandingan massa inti atom hydrogen dengan electron 1837: 1 . Muatan listrik positif yang terkumpul pada inti atom sama besarnya dengan jumlah muatan listrik negative dari electron-elektron yang mengelilingi inti, sehingga atom secara keseluruhan bersifat netral. Inti atom dengan electron akan tarik-menarik. Gaya tarik-menarik inti atom terhadap electron merupakan gaya sentripetal yang menyebabkan electron tetap beredar mengelilingi inti.

Semua atom suatu unsur mempunyai muatan inti yang unik, dan muatan ini bertambah secara teratur dari suatu unsur ke unsur lain dalam tabel periodic. Ternyata muatan ini selalu merupakan kelipatan dari $+Z e$, dengan $Z$ besar satuan muatan positif dalam inti atom suatu unsur yang dikenal sebagai nomor atom. Proton yang bermuatan +e merupakan penentu muatan inti. Nomor atom menunjukkan jumlah proton dalam inti.

Sesudah Rutherford melakukan percobaannya pada tahun 1920 partikel bermuatan listrik positif yang terdapat pada inti disebut proton. Besar muatan proton adalah $+\mathrm{e}$ $\left(1,6 \cdot 10^{-19} \mathrm{C}\right)$. misalnya atom oksigen mempunyai 8 elektron, maka inti atom oksigen mempunyai 8 proton $(Z=8)$.

Model atom Rutherford dapat diterima karena dapat diperoleh suatu rumus yang menggambarkan hamburan partikel alfa oleh selaput tipis berdasarkan model tersebut. Hasil yang diperoleh menunjukkan bahwa partikel alfa dan inti yang berinteraksi dengannya berukuran cukup kecil sehingga dapat dipandang sebagai masa titik dan muatan titik. Inti begitu massif dibandingkan dengan partikel alfa, sehingga tidak bergerak ketika berinteraksi dengan partikel alfa.

Model atom Rutherford yang telah diterima secara meyakinkan memberikan gambaran bahwa sebuah inti bermuatan posiftif dan bersifat massif dikelilingi oleh electron yang bermuatan negatif pada jarak yang relatif besar, sehingga muatan atom secara keseluruhan bersifat netral. Dalam model ini eletron tidak dapat diam, karena tidak ada sesuatupun yang dapat mempertahankannya melawan gaya Tarik inti (Wiyatmo, 2010).

Dalam Fisika Atom, model atom Bohr melukiskan bahwa atom terdiri dari inti atom yang bermuatan positif yang dikelilingi oleh electron orbit seperti susunan planet matahari. Gaya elektrostatis lebih dominan menyebabkan gaya tarik-menarik antara electron-elektron dengan inti dibandingkan dengan gaya gravitasi. Hasil eksperimen tentang spektrum atom hydrogen menunjukkan bahwa spektrum atom tersebut berupa spektrum garis yang dikenal sebagai deret Balmer. Berdasarkan hal ini dapat dikemukakan berbagai kemungkinan antara lain: model atom Rutherford salah; teori elektrodinamika klasik salah; dan model atom Rutherford dan teori elektrodinamika klasik terbatas berlakunya.

Model atom hydrogen merupakan model atom yang paling sderhana yang terdiri dari sebuah electron orbit dan sebuah inti berupa proton. Gaya-gaya yang bekerja pada atom hydrogen tersebut adalah (Wiyatmo, 2010):

- Gaya sentripetal: $F_{s}=\frac{m v^{2}}{r}$, dengan m menyatakan massa electron, $\mathrm{v}$ adalah kecepatan electron, dan $r$ jari-jari orbit electron. 
- Gaya eletrostatik: $F_{\theta}=\frac{1}{4 \pi \varepsilon_{0}} \frac{e^{2}}{r^{2}}$, dengan e menyatakan muatan elementer electron. Orbit electron akan mantap jika:

$$
\begin{aligned}
& F_{s}=F_{\theta} \\
& \frac{m v^{2}}{r}=\frac{1}{4 \pi \varepsilon_{0}} \frac{e^{2}}{r^{2}} \\
& v^{2}=\frac{1}{4 \pi \varepsilon_{0}} \frac{e^{2}}{r^{2}} \frac{r}{m} \\
& v=\frac{e}{\sqrt{4 \pi \varepsilon_{0} m r}}
\end{aligned}
$$

Reaksi Fisi Nuklir dalam Mekanisme Bom Atom

Reaksi fisi adalah reaksi pembelahan atom berat menjadi atom-atom yang lebih kecil. Reaksi fusi adalah reaksi penggabungan atom-atom ringan menjadi atom yang lebih berat. Reaksi fisi masih dibagi lagi menjadi reaksi fisi terkendali dan reaksi fisi tak terkendali. Reaksi fisi terkendali adalah reaksi inti yang terjadi di dalam reactor atom, sedangkan reaksi fisi tak terkendali adalah reaksi inti yang tejadi pada bom atom. Secara garis besar reaksi fisi dapat dijelaskan sebagai berikut:

$\mathrm{X}+\mathrm{n} \rightarrow \mathrm{X}_{1}+\mathrm{X}_{2} \ldots+(2-3) \mathrm{n}+\mathrm{E}$

Notasi pada reaksi tersebut adalah:

$\mathrm{X} \quad$ = Atom sasaran yang merupakan unsur berat yang dapat membelah sehingga sering disebut dengan bahan fisil, atau secara popular disebut dengan "bahan bakar", karena dari reaksi inti tersebut akan dihasilkan energi $(E)$.

$\mathrm{n} \quad=$ neutron penembak yang semula hanya 1 , setelah reaksi inti menjadi 2 atau 3 neutron baru.

$\mathrm{X} 1,2$ = radionuklida (unsur radioaktif) baru yang merupakan hasil dari reaksi fisi.

E = Energi yang dihasilkan dari reaksi fisi atau secara umum disebut sebagai energi nuklir.

Reaksi fisi terkendali maupun reaksi fisi tak terkendali dapat digambarkan sebagai berikut: 


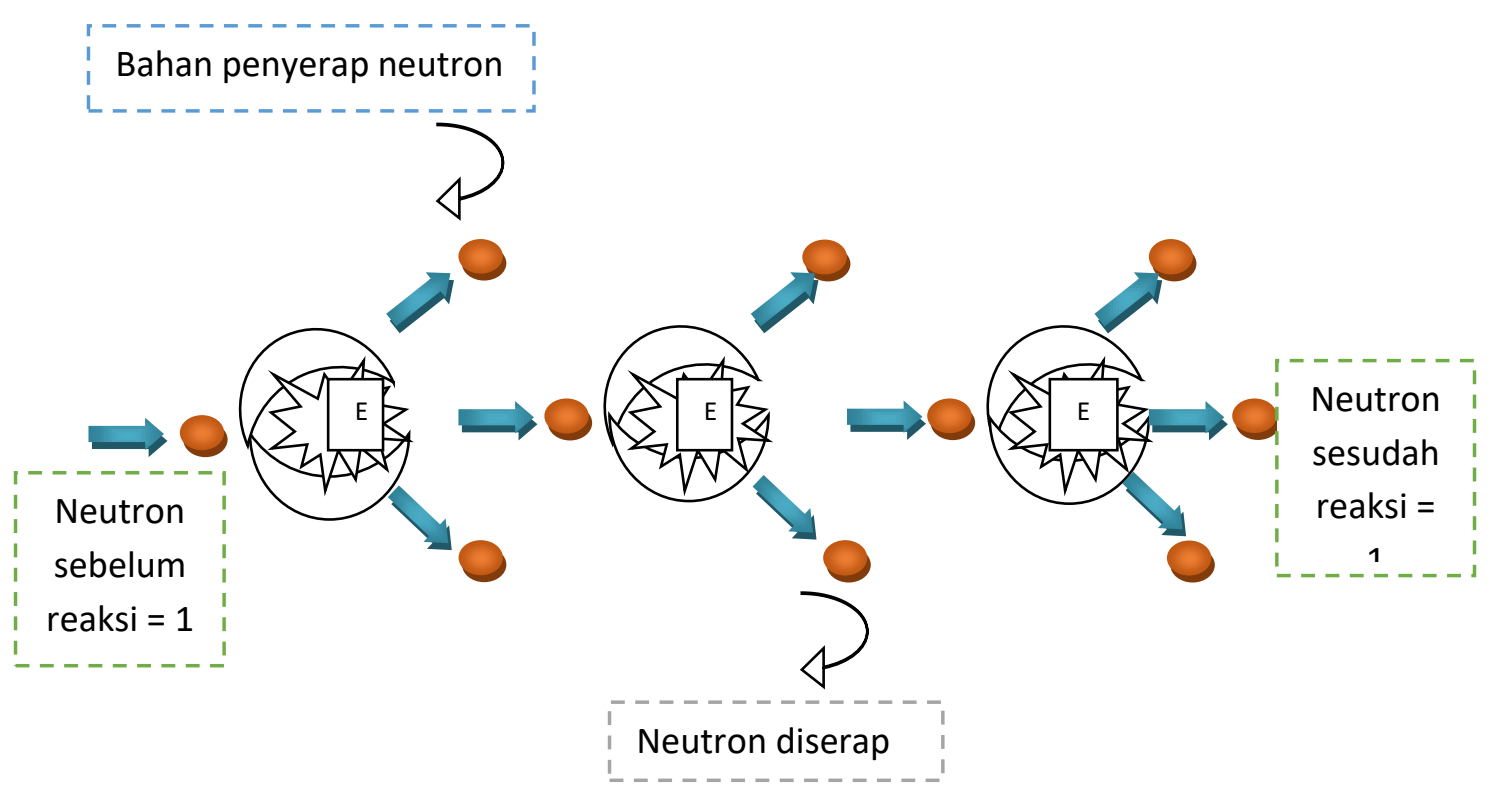

Gambar 1. Reaksi Fisi Terkendali

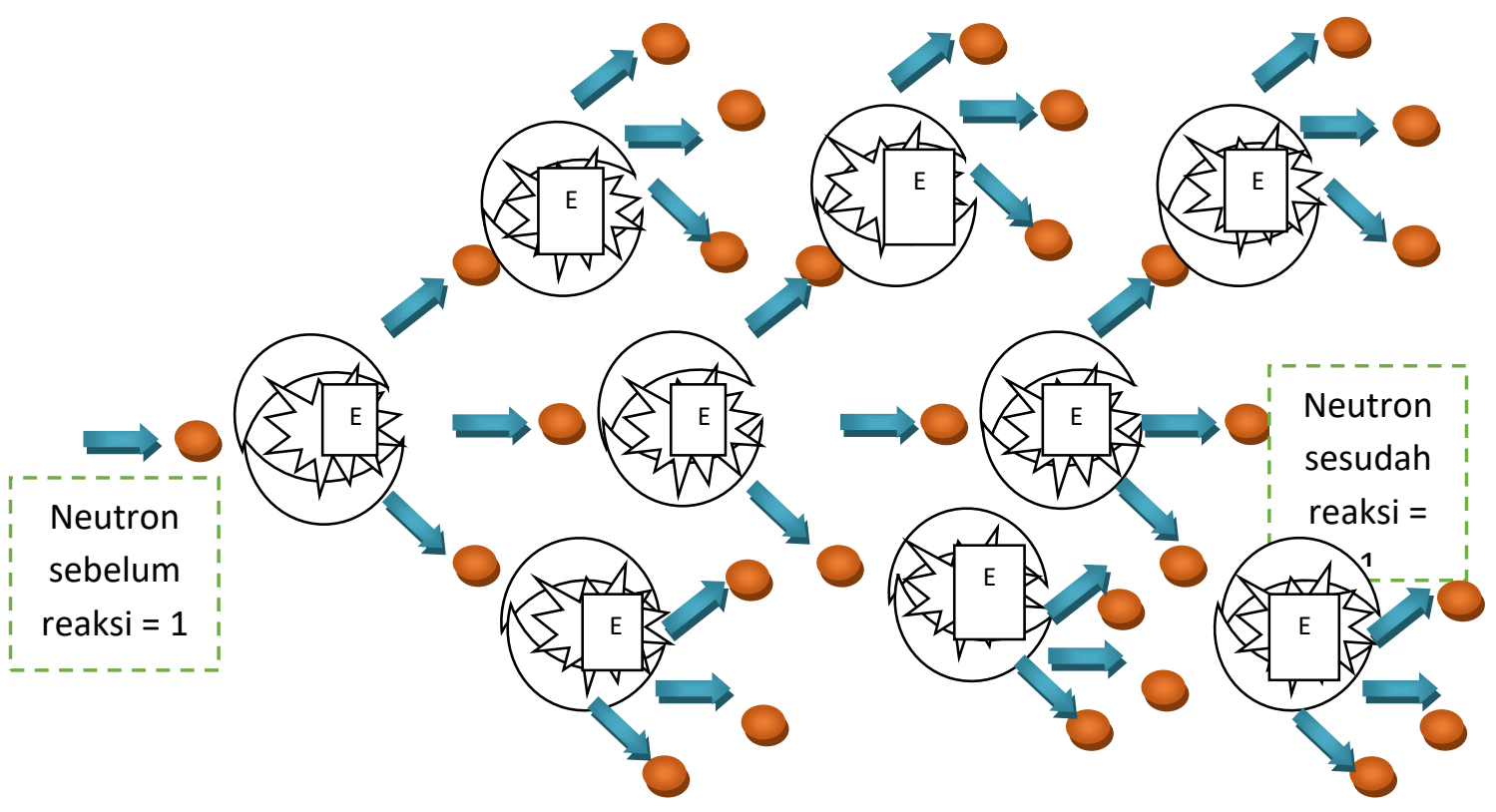

Gambar 2. Reaksi Fisi Tak Terkendali

Reaksi $X(a, b) Y$ disebut fisi jika $b$ dan y memiliki masa yang sebanding. Beberapa proses fisi terjadi secara spontan. Biasanya fisi dihasilkan hanya jika sejumlah energi yang cukup diberikan kepada inti melalui tangkapan neutron lambat, atau penembakan dengan neutron, proton, deuteron, atau sinar gamma. Sejauh ini proses fisi berlangsung melalui tahapan inti majemuk. Inti majemuk selanjutnya terpecah menjadi dua baian dan beberapa pancaran neutron.

Dalam reaksi inti ini yang mengalami pembelahan adalah atom $X$ dan terbelah menjadi atom-atom yang lebih kecil X1, X2, X3...dst nya. Sebagai pembelah adalah 
neutron yang "ditembakkan" kearah atom X. energi yang dihasilkan amat sangat besar (panasnya), energi yang sangat panas ini yang kemudian dinamakan energi nuklir. Untuk mengetahui berapa besar energi nuklir yang dihasilkan dari reaksi fisi ini, sebenarnya diperlukan pengetahuan dan perhitungan termodinamika fisika nuklir yang cukup rumit. Akan tetapi secara umum dapat dibandingkan kesetaraan panas yang dihasilkan dari reaksi fisi dengan panas yang dihasilkan oleh pembakaran batubara ataupun panas yang dihasilkan pada pembakaran minyak sebagai berikut: 1 gram Uranium $=2,5$ ton batubara $=17.500$ liter minyak.

Jadi, reaksi fisi terhadap 1 gram Uranim (atom $X$ nya) panas yang dihasilkan sama dengan panas yang dihasilkan pada pembakaran 2,5 ton batubara atau sama dengan panas yang dihasilkan pda pembakaran 17.500 liter minyak. Bukan main besar panas yang ditimbulkan oleh reaksi inti ini dan panas yang amat sangat besar ini disebut energi nuklir. Lantas kita bisa membayangkan berapa energi nuklir (panas) yang dihasilkan oleh reaksi inti terhadap 1 kilogram Uranium.

Efek yang ditimbulkan bom atom berbeda dengan kebanyakan bom konvensional terutama sekali dalam tiga hal. Pertama, tenaga yang dilepaskan dalam satu ledakan bom atom bisa mencapai satu juta kali tenaga yang timbul dalam reaksi ledakan satu jenis bahan peledak jenis high explosive dari bom konvensional dengan bobot setara. Kedua, ledakan atomic biasanya disertai pelepasan intermediat sebentuk radiasi yang tak kasat mata, berbahaya, dan berdaya tembus (penetration) tinggi. Ketiga, senyawa kimia tertentu yang tetap 'bertahan' di lokasi ledakan bahkan jauh setelah peristiwa ledakan atomic terjadi punya sifat radioaktif dan membahayakan kesehatan makhluk hidup.

Ledakan bom atom ditimbulkan oleh reaksi pembelahan (fisi) dari inti atom elemen penyusunnya, biasanya berupa uranium berbobot atom 235 (biasa disebut U-235) atau plutonium dengan bobot atom 239 (Pu-239). Kedua unsur kimia ini tergolong zat radioaktif. Tiap reaksi fisi melepaskan dengan sekaligus memancarkan neutron (partikel atomic yang tak bermuatan). Reaksi fisi yang berkesinambungan ini biasa dikenal reaksi berantai nuklir (nuclear chain reaction). Reaksi berantai ini segera menyebar ke seluruh massa zat radioaktif dalam tempo hanya dua seperjuta detik dan hanya dapat terjadi pada zat dengan jumlah massa yang cukup besar atau kerapatan yang memadai bagi terjadinya pemisahan neutron dari inti atomnya akibat pengaruh neutron lainnya yang telah lebih dahulu lepas. 


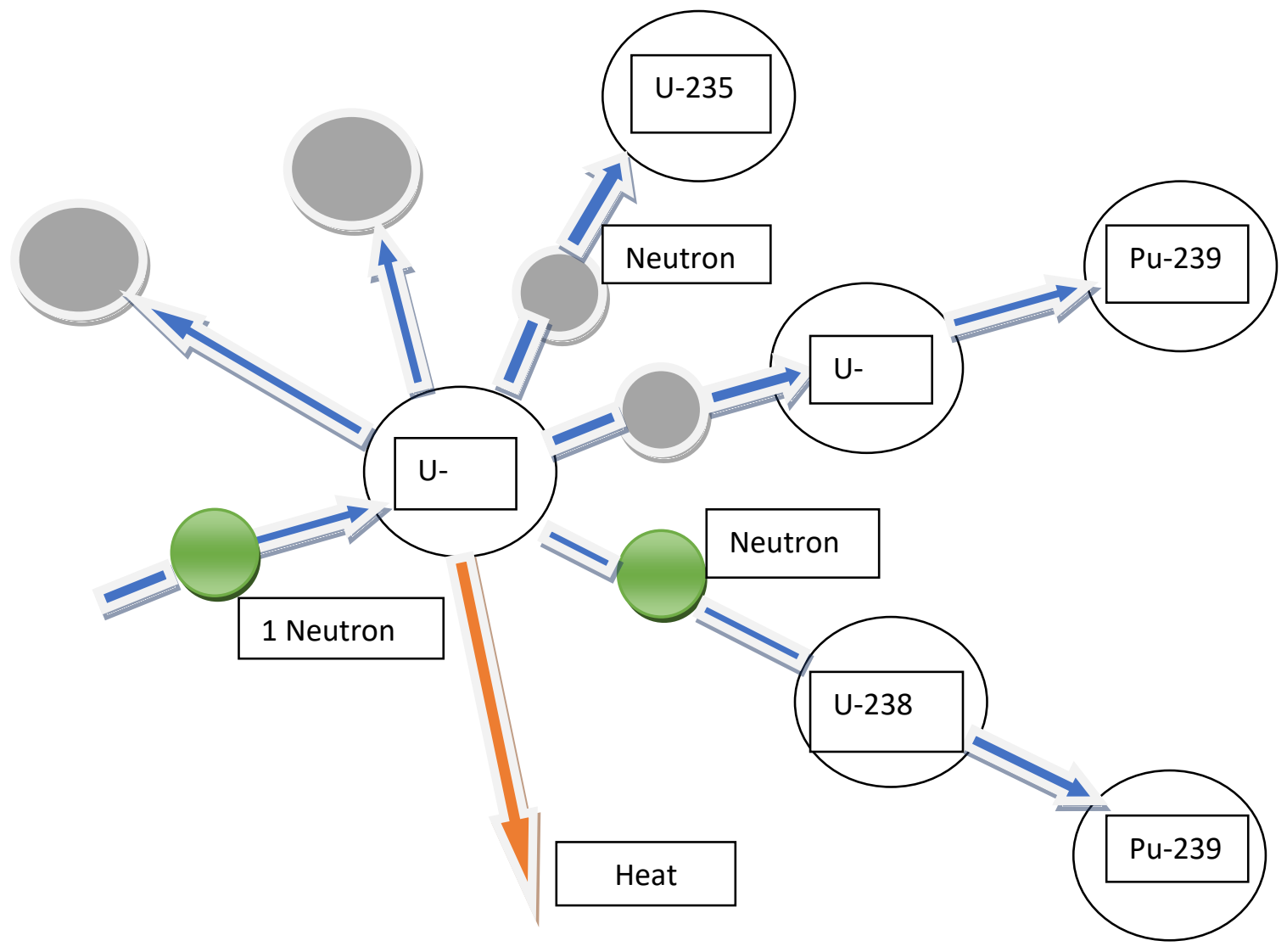

Gambar 3. Proses Fisi U-235 dengan Menembakkan Neutron

Memicu ledakan satu bom atom dapat dilakukan dengan dua cara. Dua massa elemen bom, yang mana masing-masing terlampau kecil untuk dapat meledak dengan sendirinya, saling berhimpitan satu sama lain berkat adanya pengaruh alat mekanis atau reaksi ledakan senyawa kimia dan membuahkan satu massa elemen bom yang cukup besar untuk memulai satu reaksi fisi berantai.

Selain kedua cara itu, ledakan dapat pula dipicu lewat proses pemampatan (kompresi) satu massa elemen bom dengan memanfaatkan rangkaian proses detonasi secara simultan dari sejumlah bahan peledak yang ditempatkan di sekeliling massa elemen bom tersebut. Setelah dimampatkan, derajat kerapatan massa elemen bom berhasil mencapai kondisi yang memadai guna dimulainya satu reaksi fisi.

Bagian paling vital dari ledakan fisi yang terjadi dalam bom atom tak lain adalah material yang berfisi itu sendiri. Ada dua unsur radioaktif yang biasa dipakai, yakni uranim dan plutonium, masing-masing dengan aneka isotopnya. Mulai dari U-232, U-234, U-235, dan U-238 untuk uranium, hingga Pu-238, Pu-239, dan Pu-240 untuk plutonium. Tak semua jenis istotop ini layak pakai untuk bom nuklir. Yang dibutuhkan adalah isotop yang inti atomnya sanggup menjalani reaksi fisi dengan bantuan neutron hingga berubah wujud menjadi dua isotop jenis lain plus lebih banyak neutron dan sinar gamma.

Jumlah total tenaga yang dihasilkan dalam tempo singkat dalam satu reaksi fisi sekitar 180 juta electron Volt. Artinya, dari tiap kilogram material radioaktif U-235 atau Pu-239 yang mengalami reaksi fisi secara sempurna akan dihasilkan tenaga yang setara dengan tenaga yang timbul dalam ledakan 17.000ton bahan peledak konvensional jenis TNT. Namun satu kilogram U-235 atau Pu-239 yang besarnya sebesar bola golf tidak dapat meldak dengan sendirinya karena mereka memang bukan bahan peledak. 
Jika satu inti atom mengalami reaksi fisi, maka neutron yang dihasilkan biasanya akan meninggalkan bola logam radioaktif tanpa menimbulkan reaksi fisi lanjuta. Jika bola logam tersebut mengandung 16 kilogram Pu-239 atau 50 kilogram U-235, elem bom atom dikatakan berada dalam kondisi kritis (critical condition) dan massa dari material yang terlibat dalam reaksi fisi disebut sebagai massa kritis (critical mass).

Besaran tersebut dapat ditentukan lewat jenis dan jumlah material eksternal (tamper) yang ditempatkan di sekitarnya. Material eksternal ini bertugas membelokkan sebagian neutron yang dihasilkan dalam satu reaksi fisi menuju ke material radioaktif lainnya. Lapisan U-238 setebal satu inci yang membungkus bola besi plutonium dapat menekan kebutuhan massa kritis dari 16kilogram menjadi tinggal 60 persennya.

\section{Reaksi Fusi Nuklir dalam Mekanisme Bom Termonuklir}

Menurut Agung (1998) fusi nuklir pertama kali dihasilkan di bumi pada awal tahun 30-an, dengan membombardir suatu target yang mengandung deuterium (isotop hydrogen dengan masa dua kali hydrogen) dengan deuteron berenergi tinggi pada siklotron. Untuk mempercepat pancaran deuteron, diperlukan sejumlah besar energi yang sebagian besar muncul sebagai panas pada target. Sebagai hasil, tida diperoleh energi netto yang berguna. Pada tahun 1950, pelepasan energi fusi pada skala besar namun tanpa terkendali dilaksanakan pertama kalinya sebagai uji coba senjata termonuklir oleh AS, Uni Sovyet, Inggris dan Perancis.

Reaksi fusi yang merupakan penggabungan atom-atom ringan menjadi atom yang lebih berat. Reaksi penggabungan ini dapat terjadi secara paksa, untuk dapat memaksa atom-atom kecil bergabung menjadi atom yang lebih berat diperlukan modal awal berupa panas dan tekanan yang cukup besar untuk memicu terjadinya reaksi fusi tersebut. Reaksi fusi akan menghasilkan energi nuklir (panas) yang amat sangat tinggi, jauh lebih tinggi dari energi nuklir yang dihasilkan oleh reaksi fisi. Mengingat bahwa energi nuklir yang dihasilkan oleh reaksi fusi sangat tinggi (panas), maka salah satu energi alternative untuk masa depan adlah energi dari reaksi fusi.

Reaksi fusi pada saat ini masih dalam taraf pengembangan (eksperimen) lebih lanjut untuk mendaptkan kepastian keselamatan dalam penggunaannya. Bila reaksi fusi ini berhasil dikendalikan dengan baik, maka para ilmuwan seolah-olah bisa membuat "matahari buatan" yang memberikan energi amat sangat tinggi. Contoh reaksi fusi adalah:

$\mathrm{P}$

${ }_{1} \mathrm{H}^{2}+{ }_{1} \mathrm{H}^{3} \rightarrow{ }_{2} \mathrm{He}^{4}+{ }_{o} \mathrm{n}^{1}+\mathrm{E}$

$\mathrm{T}$

Notasi reaksi fusi tersebut di atas adalah:

${ }_{1} \mathrm{H}^{2} \quad=$ atom Hidrogen dua atau atom Deuterium.

${ }_{1} \mathrm{H}^{3} \quad=$ atom Hidrogen tiga ata atom Tritium.

P $>>$ = tekanan yang sangat tinggi, sehingga wadah untuk terjadinya reaksi fusi (reactor) harus kuat agar dapat menahan tekanan tinggi tersebut.

T>> = suhu untuk memicu reaksi fusi sangat tinggi, ordenya bisa mencapai 10.000 derajat Celcius. Suhu setinggi itu dapat dicapai dengan bantuan teknologi laser.

${ }_{2} \mathrm{He}^{4}=$ atom Helium hasil reaksi fusi yang lebih berat dari pada atom ${ }_{1} \mathrm{H}^{2}$ maupun atom ${ }_{1} \mathrm{H}^{3}$. 
${ }_{0} \mathrm{n}^{1} \quad=$ neutron hasil reaksi fusi.

$\mathrm{E}>>>=\quad$ energi nuklir (panas) hasil reaksi fusi yang amat sangat tinggi. Ordenya dapat mendekati $100.000-1.000 .000$ derajat Celcius. Secara teoretis reaksi fusi dapat menghasilkan panas seperti yang terjadi di matahari.

Matahari dan binang-bintang adalah benda langit-kalau dulunya adalah sesuatu yang padu dengan bumi, berarti unsur yang ada di bumi akan terdapat juga di matahari dan akan terdapat juga di bintang-bintang. Lebi jauh para ahli astronomi memperkirakan bahwa sebagian besar unsur kimia tersebut, sekitar $80 \%$ berupa gas Hidrogen. Sedangkan unsur kedua yang banyak terdapat di matahari adalah gas Helium, kurang lebih sebanyak $19 \%$ dari seluruh massa matahari. Sedangkan sisanya yang $1 \%$ terdiri atas unsur-unsur Oksigen, Magnesium, Nitrogen, Silikon, Karbon, Belerang, Besi, Sodium, Kalsium, Nikel serta beberapa unsur trace element lainnya. Unsur-unsur kimia tersebut bercampur menjadi satu dalam bentuk gas sub atomic yang terdiri atas inti atom (nuklir), electron, proton, neutron dan positon. Gas sub atomic tersebut memancarkan energi yang amat sangat panas yang disebut plasma.

Adanya energi yang amat sangat panas ini diikuti dengan terjadinya flare, yaitu semburan partikel sub atomic keluar dari matahari menuju ke ruang angkasa. Pada saat inilah Hans Bethe menduga telah terjadi suatu reaksi termonuklir yang dahsyat. Seperti sudah dijelaskan di muka, bahwa untuk dapat terjadinya reaksi fusi perlu ada pemicu suhu yang sangat tinggi. Padahal di matahari reaktan untuk terjadinya reaksi fusi tersedia melimpah berupa gas Hidrogen, gas Helium dan partikel sub atomic. Sedangkan suhu sangat tinggi sebagai pemicu reaksi fusi berupa plasma juga sudah ada, jadi reaksi fusi yang menghasilkan energi amat sangat tinggi mudah terjadi. Reaksi fusi yang terjadi di matahari karena menghasilkan energi yang sangat tinggi sering dinamakan sebagai reaksi termonuklir.

Reaksi termonuklir yang dapat terjadi, bisa berupa reaksi fusi inti Hidrogen, reaksi fusi rantai proton-proton, reaksi pembentukan Helium dan reaksi fusi rantai KarbonNitrogen. Semua reaksi fusi tersebut menghasilkan energi yang sangat tinggi. Akan tetapi reaksi fusi yang paling tinggi energinya adalah reaksi fusi rantai Karbon-Nitrogen. Reaksi fusi rantai Karbon-Nitrogen yang menghasilkan energi amat sangat tinggi adalah sebagai berikut:

$$
\begin{array}{ll}
\mathrm{C}^{12}+\mathrm{H}^{1} \rightarrow \mathrm{N}^{13}+\mathrm{y}+ & \text { Energi nukli } \\
\mathrm{N}^{13} \rightarrow \mathrm{C}^{13}+\beta^{+}+\mathrm{v}+ & \text { Energi nuklir } \\
\mathrm{C}^{13}+\mathrm{H}^{1} \rightarrow \mathrm{N}^{14}+\mathrm{y}+ & \text { Energi nuklir } \\
\mathrm{N}^{14}+\mathrm{H}^{1} \rightarrow \mathrm{O}^{15}+\mathrm{y}+ & \text { Energi nuklir } \\
\mathrm{O}^{15} \rightarrow \mathrm{N}^{15}+\beta^{+}+\mathrm{v}+ & \text { Energi nuklir } \\
\mathrm{N}^{14}+\mathrm{H}^{1} \rightarrow \mathrm{C}^{12}+\mathrm{He}^{4}+ & \text { Energi nuklir }
\end{array}
$$

Pada setiap bagian reaksi fusi rantai Karbon-Nitrogen tersebut di atas dihasilkan energi nuklir dan penjumlahan keenam bagian reaksi fusi tersebut menghasilkan energi nuklir yang amat sangat tinggi. Bila energi tersebut ditambah dengan reaksi fusi lainnya yang terjadi di matahari, maka energi nuklir yang dihasilkan tak terbayangkan betapa amat sangat panas. 
Bom hidrogen juga kerap disebut sebagai senjata termonuklir karena untuk memulai satu reaksi ledakan nuklir dibutuhkan panas dalam jumlah besar. Dalam takaran jumlah massa yang tepat sama, tenaga yang dihasilkan sedikitnya mencapai empat kali tenaga ledakan bom atom. Sementara efek radiasinya setara dengan bom atom, hanya saja jangkauan sebarannya lebih luas.

Berbeda dengan bom atom yang mengandalkan reaksi fisi, maka bom hidrogen bertumpu pada reaksi penggabungan (fusi) dari inti dari atom hidrogen yang berbobot ringan. Dalam reaksi yang terbilang sedikit lebih rumit ini, jutaaan inti atom hidrogen 'dipaksa' oleh kondisi tekanan udara dan panas yang sangat ekstrim untuk saling berpasangan di antara sesamanya. Tiap pasang lantas menjelma menjadi inti atom helium seraya melepaskan sejumlah besar tenaga.

Ledakan bom hidrogen dapa dipicu dengan ledakan sejumlah bom atom yang berada di sekeliling massa elemen hidrogen. Akibat ledakan bom atom itu, terjadi proses pemampatan massa elemen hidrogen secara ekstrim yang disertai pelepasan panas bersuhu hingga jutaan derajat Celcius. Pada gilirannya, proses pemampatan itu mendorong terjadinya reaksi fusi dan ledakan bom hidrogen.

Perbedaan pokok antara reaksi fisi pada bom atom dengan reaksi fusi pada bom hidrogen terletak pada dua hal pokok. Secara hitungan ekonomis, biaya awal yang dikeluarkan agar dapat menyelenggarakan satu reaksi fusi jelas lebih besar ketimbang reaksi fisi. Namun sekali reaksi fusi telah berjalan, maka tenaga yang dihasilkannya akan relative lebih murah. Selain itu, efek radioaktif yang dibangkitkan dalam satu reaksi fusi ternyata lebih gampang dimodifikasi ketimbang efek radioaktif pada bom atom. Dengan begitu lebih terbuka peluang untuk menciptakan bom yang lebih bersih. Artinya, jumlah partikel radioaktif berbahaya yang tertinggal setiap usai ledakan dapat ditekan hingga seminimal mungkin.

Pada intinya ada empat kondisi yang terjadi dalam setiap reaksi nuklir. Pertama, reaksi langsung dan berantai antara inti atom dan neutron. Kedua, sejumlah kecil inti atom diakselerasikan dalam laboratorium agar memiliki kecepatan yang tinggi sehingga beberapa di antaranya saling bertumbukan dan terjadi reaksi. Ketiga, reaksi tumbukan yang terjadi antara partikel matahari dan bintang di akwasan antariksa dalam kondisi temperature tinggi yang sangat ekstrem. Reaksi ini disebut reaksi termonuklir alam. Sementara pada kondisi yang terakhir, fenomena alam yang terjadi antara matahari dengan bintang tadi direkasaya sedemikian rupa dan diaplikasikan ke dalam bentuk senjata pemusnah massal. Dalam reaksi termonuklir buatan manusia, kecepatan dan temperature reaksinya jauh lebih tinggi daripada yang terjadi di matahari.

Elemen pemicu ledak yang biasa dipakai dalam ledakan termonuklir ialah deuterium (D) alias hydrogen berat atau yang juga popular dengan sebutan 'air berat' (heavy water). Dari setiap 5000 atom hydrogen, bisa dipastikan satu isotop di antaranya dalam bentuk deuterium. Inti deuterium (deutron) terdiri dari satu proton ( $p$ ) dan satu neutron $(n)$. Saat berpasangan, dua deutron membentuk inti atom helium (He-4) yang relative stabil. Namun ada kalanya dapat juga membentuk isotop hydrogen yang lebih berat, yakni tritium ( $\mathrm{T}$ ) disertai satu proton atau inti dari isotop helium yang berbobot tiga ( $\mathrm{He}-$ 3) plus satu neutron. Sementara jika deuterium beeaksi dengan tritium, maka akan dihasilkan atom helium dan satu neutron. Serta reaksi antara inti atom litium (Li-6) dengan neutron akan membuahkan atom helium dan tritium. Dalam semua jenis reaksi ini, inti atom berat terbentuk melalui proses fusi sehingga wajar jika bom hydrogen kerap dijuluki sebaga bom fusi.

Secara garis besar, tahapan dalam ledakan bom hydrogen dapat dipaparkan sebagai berikut. Senyawa litium deuteride (Li6D) ditempatkan dalam satu selongsong (casing) yang terbuat dari isotop radioaktif U-238 bersama dalam bola bahan kimia peledak jenis TNT yang di dalamnya diisi isotop radioaktif U-235. Detonasi TNT memampatkan U-235 hingga mendorong terjadinya reaksi fisi yang membuat lepasnya partikel neutron disertai peningkatan temperature hingga mencapai jutaan derajat celcius. Tenaga termal yang timbul harus cukup kuat untuk menimbulkan tolakan elektrik 
yang membuat neutron kemudian dapat menghantam inti atom litium dan berubah wujud menjadi isotop helium dan tritium. Pada gilirannya, tritium akan berfusi dengan deuterium (dalam Li6D) dan membentuk lebih banyak neutron. Beberapa neutron membentur selongsong U-238 sehingga terjadi reaksi fisi selanjutnya.

\section{KESIMPULAN}

Melalui rekayasa perilaku interaksi antara sejumlah isotop dari atom berbobot berat dengan partikel non atomic berkecepatan tinggi dihasilkan beberapa reaksi fisi dan fusi yang menghasilkan tenaga mahadasyat. Aplikasi militer dari fenomena fisika ini membuahkan senjata pemusnah massal dengan daya rusak dan bunuh mengerikan. Ada ratusan jenis atom di dunia ini yag dibedakan melalui ukuran dan komposisi inti atom serta jumlah electron yang mengitarinya. Uranium merupakan atom terberat yang tergolong kasat mata dan mempunyai potensi untuk bersifat tak stabil. Istilah berat disini mengacu pada jumlah proton yang ada di dalam intinya. Potensi ketidakstabilan uranium dapat memicu lepasnya tenaga dalam jumlah besar saat atom ini memecah. Ada dua bentuk isotop uranium, yakni U-238 (92 proton + 146 neutron) yang jumlahnya mayoritas dan U-235 (92 proton +143 neutron). Berdasarkan deskripsi yang diberikan dalam penelitian ini, maka sudah seharusnya bahwa penguasaan energi yang sangat besar diambil kemanfaatannya untuk kepentingan umat manusia dan secara bertahap mengurangi penggunaannya dalam aplikasi untuk senjata pemusnah massal mengingat daya rusak dan bunuh yang mengerikan.

\section{DAFTAR PUSTAKA}

Agung, Alexander. (1998). Fusi Nuklir: Sumber Energi Masa Depan. Jurnal Energi, 1(1), 28-30.

Basri, Teuku Hasan. (2014). Sejarah dan Perkembangan Senjata Nuklir. Jurnal Seuneubok Lada, 2(1), 6-105.

Kholil, M., \& Apriyono, F. (2018). Identifikasi Konsep Matematika Dalam Permainan Tradisional Di Kampung Belajar Tanoker Ledokombo Jember . Indonesian Journal of Islamic Teaching, 1(1), 62-75.

Lapp, Ralph E. (1961). Man and Space: The Next Decade. New York: Harper \& Brothers.

Maemunah, Rosidah Indah, dkk. (2019). Studi Komparasi Reaksi Fisi dan Fusi Pada Pembangkit Listrik Tenaga Nuklir Masa Depan. Prosiding Seminar Nasional Fisika 5.0, 473-481.

Russel, Bertrand. (1960). The ABC of Relativity. New York: Mentor Books.

Sukarna, I Made. (1997). Kajian Kestabilan Inti dengan Pendekatan energi Pengikat Inti. Jurnal Cakrawala pendidikan, 16(1), 165-175.

Wardhana, Wisnu Arya. (2009). Al-Quran dan Energi Nuklir. Yogyakarta: Pustaka Pelajar.

Wiyatmo, Yusman. (2010). Fisika Atom: dalam Perspektif Klasik, Semiklasik dan Kuantum. Yogyakarta: Pustaka Pelajar.

Wiyatmo, Yusman. (2010). Fisika Modern. Yogyakarta: Pustaka Pelajar.

Wiyatmo, Yusman. (2014). Fisika Nuklir dalam Telaah Semiklasik dan Kuantum. Yogyakarta: Pustaka Pelajar. 